It has become increasingly popular for forest research workers to rely on instruments, gadgets and various mechanical and electrical contrivances to carry on their work. In the eyes of many an administrator, the number and complexity of gadgets used by a research worker has become one criterion of that worker's ability. Instruments may be invaluable both in the laboratory and the field but simply because the scale of an instrument reads to the nearest tenth of a unit does not mean that readings of this order have any significance. Soil reaction $(\mathrm{pH})$, for example, can be measured in various ways ranging from the use of coloured dyes to a very elaborate electric meter with a corresponding precision from one half of a unit to one hundredth of a unit. For most soils a reading of 6.38 obtained electrometrically has no more significance that a reading of 6.5 obtained by using a dye.

During the past two or three years the writer has observed a number of experiments dealing with young trees, and it has been apparent that the trees themselves were unhealthy - a condition in no way related to the experimental treatments. It would seem obvious that the results of experiments performed with invalid stock are not applicable to healthy normal trees. For example, the results of an experiment concerned with the effect of light on the growth of jack pine are of little consequence if the trees suffer from a nitrogen deficiency.

Lastly, a number of research workers in forestry apparently have the notion that their work is of primary interest to botanists, soil scientists, etc., rather than to foresters. Perhaps, they are merely looking for recognition from what they deem to be more august disciplines. In any event there is a trend amongst Canadian forest research workers to neglect their colleagues in general practice and to consider that problems of a fundamental nature are more important than practical ones. The result is often an unfortunate gap between forest research and current practice.

This does not mean that forestry cannot benefit from the findings of other sciences. Communications between scientists in all fields are to be encouraged. What should be realized is that apart from an obligation to his employer the research worker in forestry has a further special responsibility to that profession and all those working in it.

\section{Developments In Federal Forestry Organization}

Recognition by the Federal Government of the importance of forestry to Canada was quite recently foreshadowed by the appearance of two items in the 1959 September and December issues of The Forestry Chronicle. The first was a brief by Prof. D. V. Love of the University of Toronto to the House of Commons Standing Committee on Mines, Forests and Waters, and the second was an extract from the final report of the above Commons Committee recommending among other things the establishment of a new federal department responsible for forestry.

Representations were made by eighteen forest industry leaders and other important forest authorities to the House of Commons Committee during its 1958-59 sittings. The biggest delegation, headed by T. N. Bieaupré, President of Columbia Cellulose Corp., came from British Columbia.

The sequence of major events in the Federal Government's actions in 